\section{Australian Journal of \\ Crop Science}

\title{
Growth-promoting activity of indigenous Trichoderma isolates on wheat seed germination, seedling growth and yield
}

\author{
Behzad Hajieghrari $^{1}$, Mohammadreza Mohammadi ${ }^{2}$ \\ ${ }^{1}$ Department of Agricultural Biotechnology, College of Agriculture, Jahrom University, PO BOX 74135-111, \\ Jahrom-IRAN \\ ${ }^{2}$ Department of Plant Protection, Faculty of Agriculture, Varamin Branch, Islamic Azad University, Varamin, \\ Tehran-IRAN
}

*Corresponding author: bheghrari@yahoo.com; b.hajieghrari@yahoo.com

\begin{abstract}
Apart from their biocontrol potential, Trichoderma rhizosphere-competent strains stimulate plants growth via several direct mechanisms that affect various growth parameters. In this study, effect of five indigenous isolates (T. harzianum T 969, T. harzianum T 447, T. hamatum T 614, Trichoderma sp. isolate T and Gliocladium virens G525.) on wheat (variety Moghan 3) seed germination, seedling vigor and plant growth was examined through seeds treatment by the conidia and culture filtrate of the isolates. In the field experiments various growth parameters including rootlet and shoot length, stem height and weight, root length and weight, total leaf area, head and tiller number and 1000 grain weight as well as the plant total chlorophyll content and stomata conductance response were evaluated. In overall, seed germination rate was increased. The highest seed germination rate (95.8\%) was observed for $T$. harzianum T969 non-sterilized cultural filtrate treatment and after 96 hours. The isolate G. virens G525 spore treatment decreased the rate by $54.5 \%$. Although all isolates colonized on rootlets but no significant effect on the seedlings growth was observed. Isolate $T$. hamatum T614 caused necrotic reaction on rootlets, revealing its parasitic rather than symbiotic activity. In the field experiments, the isolates had significant effect on parameters such as stomata conductance, 1000 grain weight, ear fresh and dry weights, ear length and stem and root dry weight but they showed no significant effect on other evaluated parameters. Some isolates improved the affected parameters and some had negative effects which are discussed.
\end{abstract}

Keywords: Trichoderma; wheat; seed germination; seedling vigor; plant growth.

\section{Introduction}

Agricultural soils around the world are under increasing pressure by input of huge amounts of chemical fertilizers to ensure crops high productivity and yield for growing human population. However, considering the many negative environmental and health consequences attributed to the use of inorganic fertilizers in agriculture and in order to achieve a sustainable and environmental-friendly agriculture, the use of such substances should be reduced and other eco-friendly and nature-based substances should be developed for improvements in the crops growth and yield (Gentili and Jumpponen, 2006, Hermosa et al., 2012, Bhardwaj et al., 2014). Biofertilizers are one of the environmental-friendly alternatives to the chemical fertilizers that are being marketed with the aim to increase the soils fertility and the crops productivity and yield without causing harmful environmental effects. These products also play important role in organic farming (Mihov and Tringovska, 2010, Hermosa et al., 2012). Biofertilizers are based on the microorganisms (fungi and rhizobacteria) that are able to colonize rhizosphere of the plants and promote plants growth and enhance their tolerance to the biotic and abiotic stresses via various mechanisms (Fuentes-Ramirez and CaballeroMellado, 2005; Naganada et al., 2010). The fungus Trichoderma (Teleomorph: Hypocrea, an ascomycete), a ubiquitous fungus and common inhabitant of all soils and rhizospheres, and also common symbiont of the plants roots, has been an important component of biofertilizers (Vinale et al., 2014, Sharma et al., 2012). It is a biocontrol agent that beside antagonistic capabilities in suppression and control of soil-borne plant pathogenic fungi has also shown promising plant growth promoting potential (Harman et al., 2004, Druzhinina et al., 2011, Raats, 2012, Martínez-Medina et al., 2014). As an effective biocontrol agent, Trichoderma has been an important component of biofungicides with the aim to promote plants health avoiding the many negative effects of chemical fungicides on environment and human health ( $\mathrm{Lu}$ et al., 2004, Topolovec-Pintarić et al., 2013, Maag et al., 2014). However, the results of investigations have highlighted the fungus abilities in enhancing plants growth independent from its antagonistic potential in suppression of plant pathogens (Contreras-Cornejo et al., 2009, TopolovecPintarić et al., 2013). Beneficial effects of Trichoderma as plant growth stimulator and promoter are attributed to several discovered mechanisms which include root colonization as endophyte symbiont, solubilization of the minerals and increasing availability of insoluble nutrients and therefore plant nutrient uptake, secretion of siderophores, plant growth regulatory materials (phytohormons), vitamins and enzymes (such as phosphate-solubilizing enzymes) (Anke et al., 1991, Benítez et al., 2004, Harman, 2006, Gravel et al., 2007, de Santiago et al., 2011, Li et al., 2015). The plant growth promoting activity of Trichoderma has been demonstrated in 
a wide variety of crops including tobacco, tomato and radish (Windham et al., 1986), strawberries (Porras et al., 2007), lettuce (Bal and Altintas, 2008), onion (Altintas and Bal, 2008), cotton (Shanmugaiah et al., 2009), tomato (Gravel et al., 2007, Morsy et al., 2009), bean (Hoyos-Carvajal et al., 2009, Raats, 2012, Erper et al., 2013), soybean (John et al., 2010, Entesari et al., 2013), chickpea (Yadav et al., 2011), tulip (Mazahebi et al., 2011), apple (Raman, 2012), sunflower (Badar and Qureshi, 2012), wheat (Sharma et al., 2012), cabbage and red beet (Topolovec-Pintarić et al., 2013), rice (Doni et al., 2014a,b), gray mangroves (Saravanakumar et al., 2013) and potato (Hicks et al., 2014). Search for Trichoderma species, strains and isolates with higher growthpromoting activity is one of the fields of interest for scientists around the world. This is because the plant growth promoting potential varies amongst different Trichoderma species and strains, and also indigenous isolates are usually favored for subsequent use as biofertilizer (Martínez-Medina et al., 2014). These isolates can be formulated in combination with other rhizomicrobes and marketed for use as replacement to the chemical fertilizers.

Despite of intensive chemical fertilizers application and due to various abiotic stresses especially drought, the average yield of wheat crop, the main food crop in Iran, is low. Locally formulated biofertilizers also are not diversely available in the market for diverse number of crops grown countrywide, including wheat. Search for and screening of the indigenous microorganisms with higher growthpromoting potential to be used for manufacturing biofertilizers is essential step towards achieving satisfactory average yield and reduction of chemical fertilizers application. Thus, addressing this necessity and for the first time the plant growth promoting potential of some indigenous Trichoderma isolates on a local and mostcultivated wheat cultivar in Iran and their effect on various growth parameters such as seed germination, seedling growth and grain yield was studied.

\section{Results}

\section{Effect of Trichoderma isolates on wheat seed germination and seedling vigor}

Effect of sterilized and non-sterilized Trichoderma isolates cultural filtrate was examined on wheat seed germination, seedling height and rootlet length, crown diameter, shoot and rootlet fresh weight and leaf number. Sterilized and nonsterilized metabolites had marked effect $(\mathrm{P} \leq 0.01)$ on seed germination rate $(89.22 \mathrm{~b}$ for sterilized Trichoderma metabolite vs. $94.56 \mathrm{a}$ for non-sterilized Trichoderma metabolite; the main effect of metabolite sterilization). Nonsterilized filtrate significantly $(\mathrm{P} \leq 0.01)$ affected seed germination but had no effect on final seedling rootlet and shoot length $(\mathrm{P} \geq 0.05)$ two weeks after placing inoculated seeds on sterile blotting paper. In heat-sterilized cultural filtrate treatments no significant difference was observed among the treatments and the controls (non-inoculated and double distilled watered seeds) since all had no effect on seed germination and rootlet and shoot length $(\mathrm{P} \geq 0.05)$. The highest seed germination rate was observed for T. harzianum T969 non-sterilized cultural filtrate and 96 hours after treatment (Fig. 1). Seed germination rate in T. harzianum T447 non-sterilized cultural filtrate treatment and control was the same and other three Trichoderma treatments had no significant effect compared with the control and T. harzianum T969 cultural filtrate treatment (Fig. 1). Direct inoculation of seeds by Trichoderma isolates spores had significant effect
$(\mathrm{P} \leq 0.01)$ on seed germination but had no effect on seedling rootlet and shoot length and weight $(\mathrm{P} \geq 0.05)$. T. harzianum T969 spores inoculation significantly $(\mathrm{P} \leq 0.01)$ increased seed germination while inoculation of the seeds by $G$. virens $\mathrm{G} 525$ spores decreased and other three Trichoderma treatments had no effect on seed germination (Fig. 2). Microscopic observation of the roots of the seedlings grown in presence of Trichoderma isolates revealed complete attachment of the fungal hyphae to the root surface. Large mass of fungal hyphae grown on roots surface presented colonization of the rhizosphere by the isolates and intimate contact with the host root exodermises (Fig. 3, A). Transverse section of the root in T. hamatum T614 -treated seedlings showed that the fungus was able to penetrate the root epidermis and progress towards the cortical area mainly by intercellular growth facilitating fungal spread into the root tissue (Fig. 3, B and C). T. hamatum T614 penetrated the root system without causing extensive damage in initial stages (Fig. 3, D and E). In the early stages the cells might be sensitized to trigger the transient elaboration of the host defense reaction and respond faster to greater extent to potential pathogen attacks. In this sense, necrotic region was observed in the inner layer of rootlet emerged from $T$. hamatum T614 -inoculated seeds indicating its parasitic rather than symbiotic function (Fig. 4). T. hamatum T614 was re-isolated from the necrotic region.

The effect of Trichoderma isolates on culture media was also evaluated and it was observed that Trichoderma isolates significantly decreased the $\mathrm{pH}$ and affected $\mathrm{EC}$ and $\mathrm{K}+$ and $\mathrm{Na}+$ content of the media (Table 1).

\section{Effect of Trichoderma isolates on wheat growth in field condition}

No marked $(\mathrm{P} \geq 0.05)$ differences were observed between the two experimental fields in two separate locations. Results of both field experiments showed that treatment of wheat plants with Trichoderma isolates had statistically significant effect $(\mathrm{P} \leq 0.05)$ on stomata conductivity, 1000 grain weight, ear fresh and dry weights, ear length, and stem and root dry weight, but had no effect on other evaluated parameters. Stomatal conductance was significantly $(\mathrm{P} \leq 0.05)$ affected by Trichoderma isolates. It was significantly decreased $(\mathrm{P} \leq 0.05)$ in $T$. harzianum T447-treated wheat plants comparing with the control (Fig. 5). Significantly great values $(\mathrm{P} \leq 0.05)$ were obtained in grain weight for Trichoderma-treated wheat plants compared with the control. However, G. virens G525 treatment showed the greatest increase in grain weight (Fig. $6)$. Ear dry weight was significantly $(\mathrm{P} \leq 0.05)$ higher for $T$. harzianum T969 -treated wheat plants. Other Trichoderma isolates did not show significant effect compared with the control except for $T$. hamatum T614 that significantly $(\mathrm{P} \leq 0.05)$ decreased ear dry weight (Fig. 7). In contrast, Trichoderma-treated wheat plants showed significant decrease in ear fresh weight. Amongst the isolates, $T$. hamatum T614 had the greatest effect on ear fresh weight (Fig. 7).

It was also observed that the length of wheat ear was significantly $(\mathrm{P} \leq 0.05)$ shorter in Trichoderma-treated plants in comparison with the control. In particular, T. hamatum T614 had greater effect in reducing the ear length compared to the other isolates (Fig. 8). In addition, in Trichodermatreated wheat plants stem and root dry weight was decreased. Significant decrease $(\mathrm{P} \leq 0.05)$ was observed in $G$. virens G525-treated plants (Fig. 9). However, no significant decrease in stem and root dry weight was seen in other Trichoderma isolates-treated wheat plants (Fig. 9). No 
Table 1. Effect of Trichoderma isolates/species on culture medium.

\begin{tabular}{lllll}
\hline Treatments & $\mathrm{pH}$ & $\mathrm{EC}(\mathrm{mho} / \mathrm{cm})$ & $\mathrm{Na}^{+}(\mathrm{ppm})$ & $\mathrm{K}^{+}(\mathrm{ppm})$ \\
\hline Control (No inoculation) & 6.64 & 2.7 & 5.272 & 5.009 \\
Trichoderma harzianum T969 & 2.88 & 2.72 & 4.840 & 4.980 \\
Trichoderma harzianum T447 & 3.4 & 2.37 & 5.542 & 5.330 \\
Trichoderma sp. T & 2.87 & 2.94 & 6.022 & 5.886 \\
Gliocladium virens G525 & 4.2 & 2.76 & 2.864 & 5.477 \\
Trichoderma hamatum T614 & 3.01 & 2.56 & 4.142 & 5.097 \\
\hline
\end{tabular}

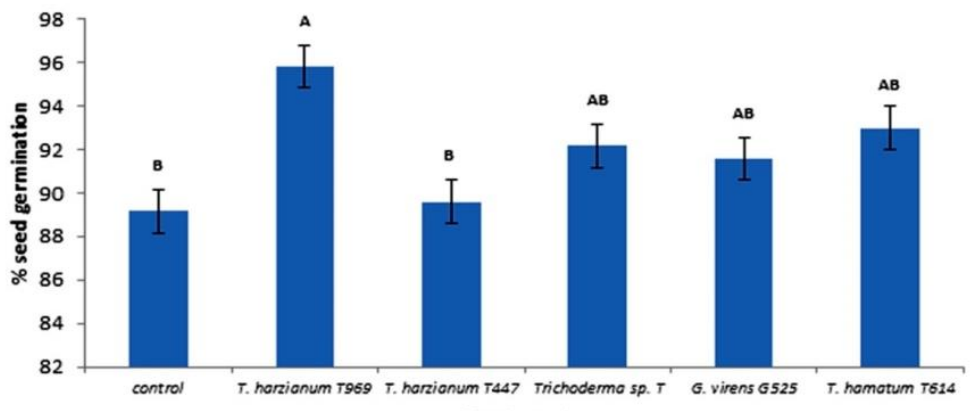

Treatments

Fig 1. Effect of Trichoderma isolates non-sterilized cultural filtrate on wheat seed germination 96 hours after treatment (The main effect of Trichoderma isolates). Data are expressed as \% of germinated seeds and values are average of 4 replications. Means with the same letter are not significantly different $(\mathrm{P} \geq 0.01)$ by Duncan's Multiple Range Test for variable.

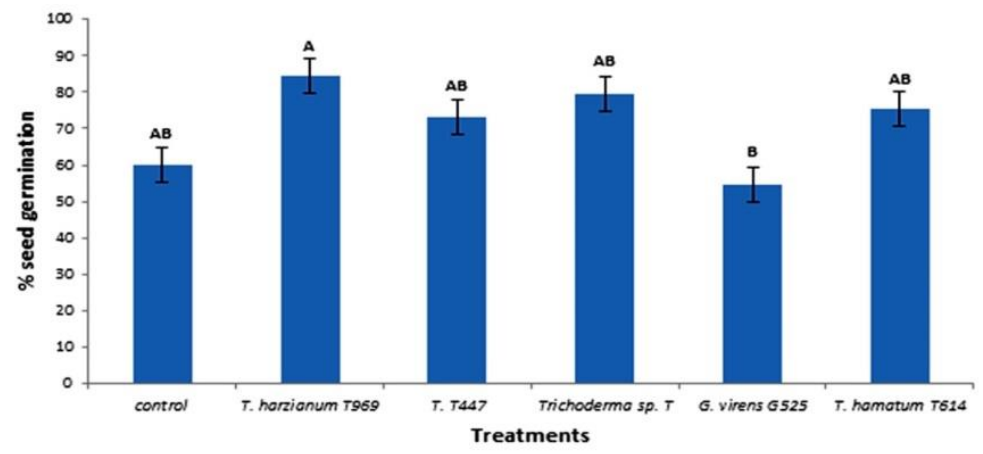

Fig 2. Effect of Trichoderma isolates spore inoculation on wheat seed germination (The main effect of Trichoderma isolates). Data are expressed as \% of germinated seeds and values are average of 4 replications. Means with the same letter are not significantly different $(\mathrm{P} \geq 0.01)$ by Duncan's Multiple Range Test for variable.
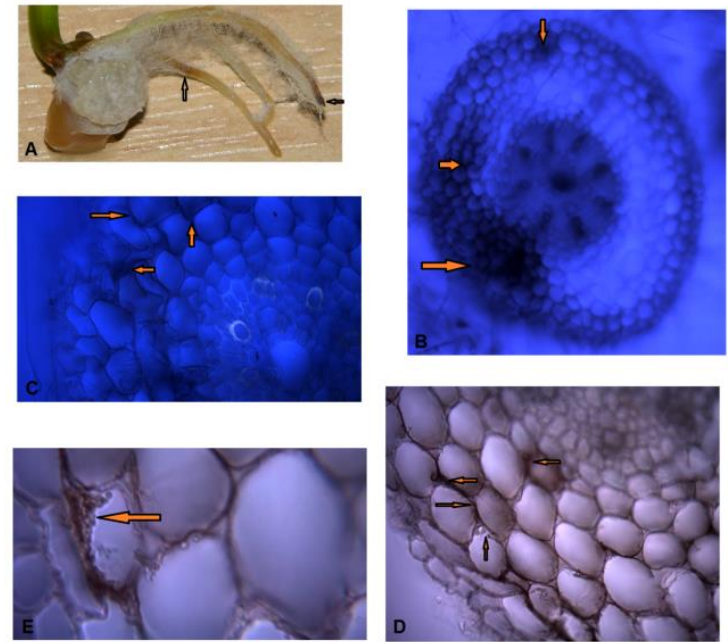

Fig 3. Colonization of the wheat rootlets by Trichoderma hamatum T.614, the isolate which showed parasitic activity and caused necrotic area in rootlet cortex; a large mass of fungal hyphae developed on the rootlets and seed surface as indicated by arrow (A). Its hyphae penetrated the rootlet epidermis and progressed towards the rootlet cortical area by intercellular growth (indicated by arrows) and it was not associated with the host cells alteration or cells wall digestion (B-E). 

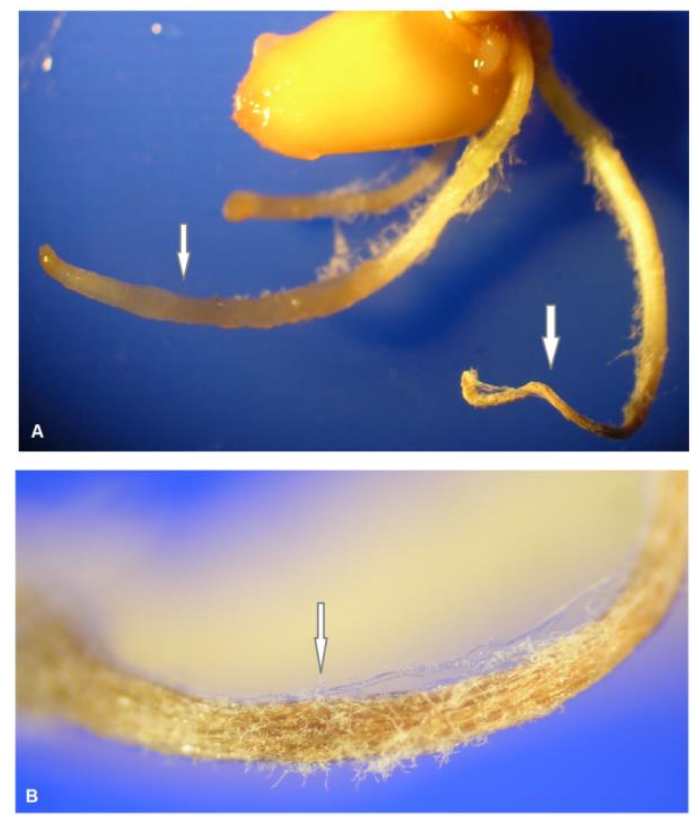

Fig 4. Necrotic regions (indicated by arrows) developed in the inner layer of emerged rootlet from T. hamatum T.614-inoculated seeds (A and $\mathbf{B})$.

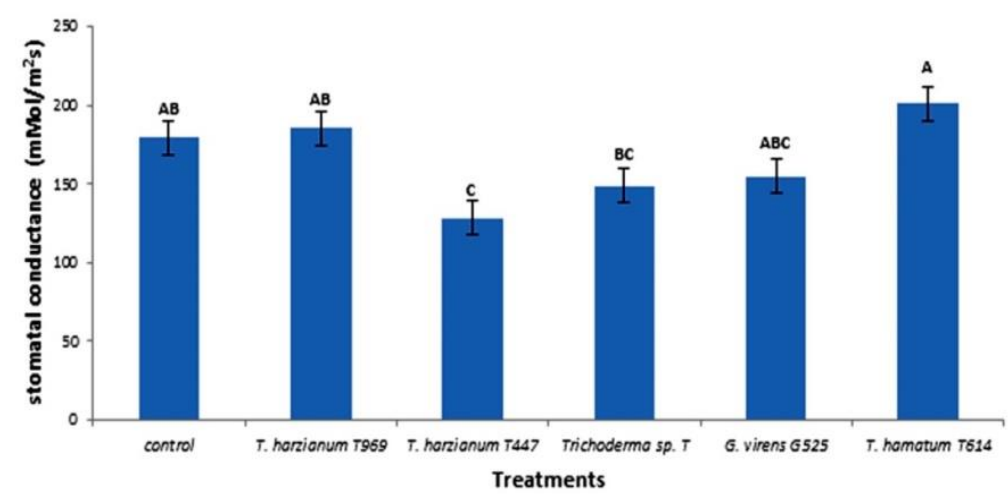

Fig 5. Effect of Trichoderma isolates on wheat stomatal conductance (The main effect of Trichoderma isolates). Data are expressed as means of stomatal conductance $\left(\mathrm{mMol} / \mathrm{m}^{2} \mathrm{~s}\right)$ and values are average of 8 blocks. Means with the same letter are not significantly different $(\mathrm{P} \geq 0.05)$ by Duncan's Multiple Range Test for variable.

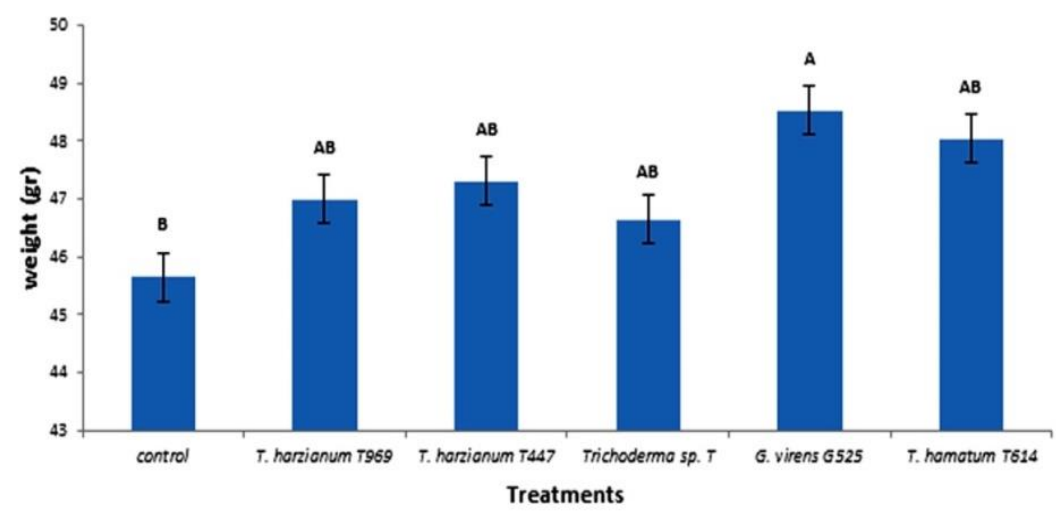

Fig 6. Effect of Trichoderma isolates on wheat grain weight (The main effect of Trichoderma isolates). Data are expressed as means of 1000 grains weight (gr) and values are average of 8 blocks. Means with the same letter are not significantly different $(\mathrm{P} \geq 0.05)$ by Duncan's Multiple Range Test for variable. 


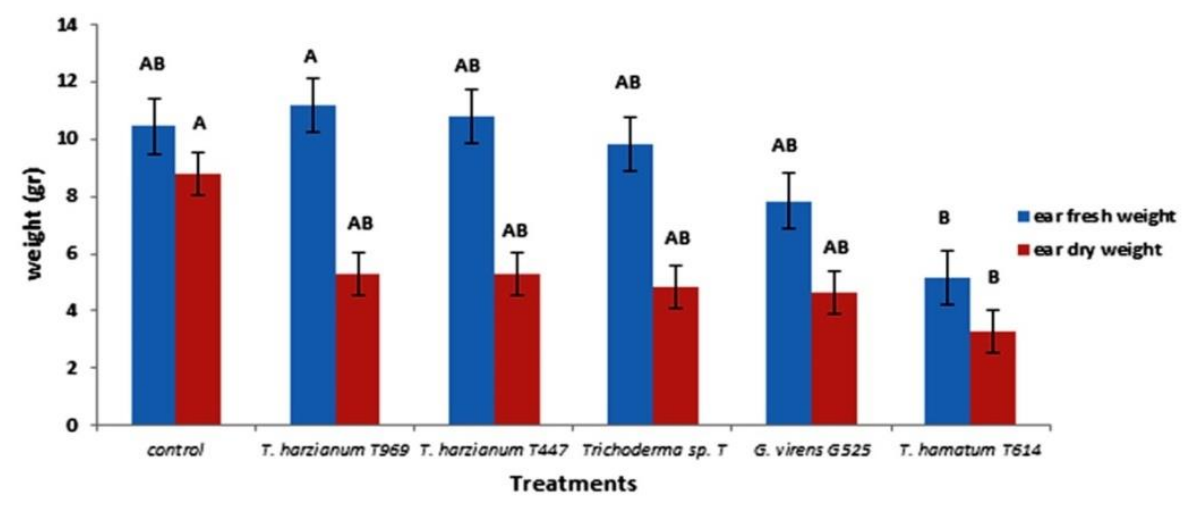

Fig 7. Effect of Trichoderma isolates on wheat ear fresh and dry (The main effect of Trichoderma isolates). Data are expressed of the average of 8 blocks. Means with the same letter are not significantly different $(\mathrm{P} \geq 0.05)$ by Duncan's Multiple Range Test for variable.

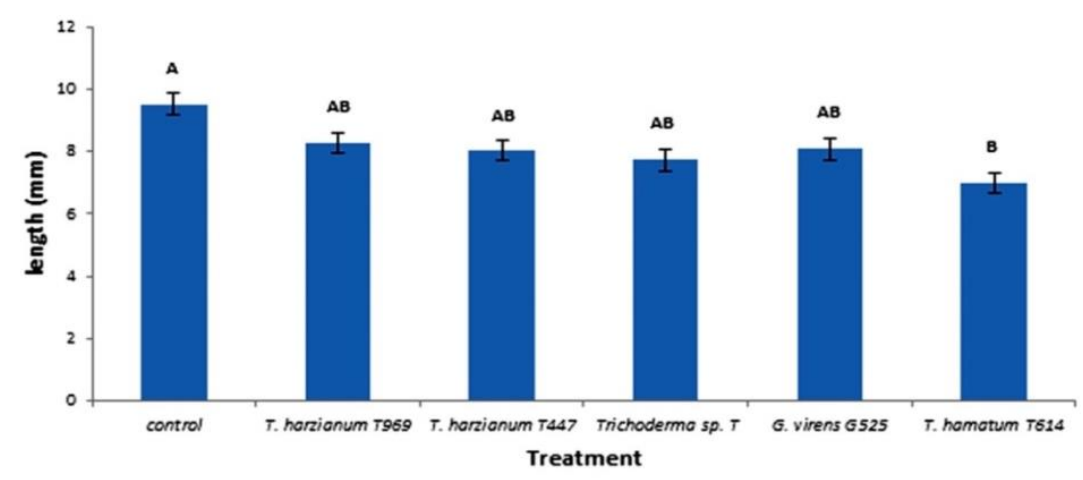

Fig 8. Effect of Trichoderma isolates on wheat ear length (The main effect of Trichoderma isolates). Data are expressed as means of ear length $(\mathrm{mm})$ and values are average of 8 blocks. Means with the same letter are not significantly different $(\mathrm{P} \geq 0.05)$ by Duncan's Multiple Range Test for variable.

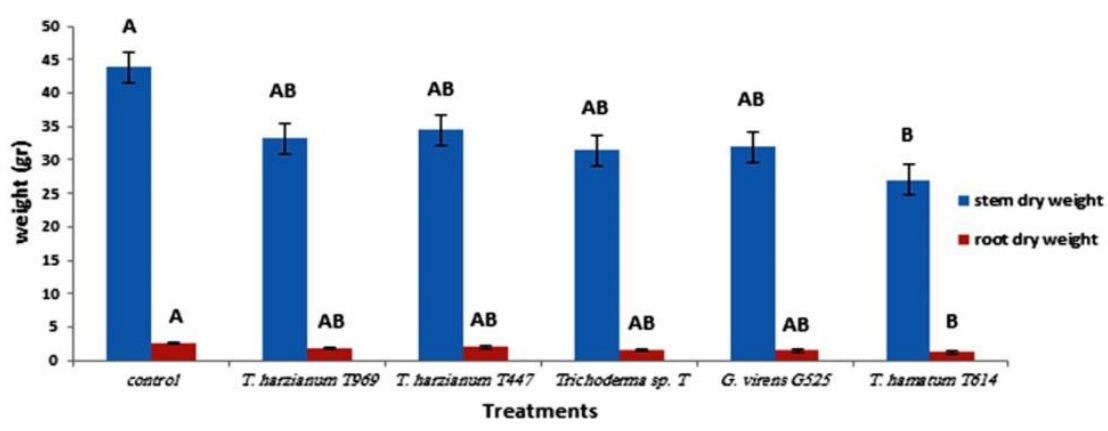

Fig 9. Effect of Trichoderma isolates on wheat stem and root dry weight (The main effect of Trichoderma isolates). Data are expressed of the average of 8 blocks. Means with the same letter are not significantly different $(\mathrm{P} \geq 0.05)$ by Duncan's Multiple Range Test for variable.

significant improvement in other measured parameters was seen for the Trichoderma-treated wheat plants.

\section{Discussion}

In the recent years, certain strains of Trichoderma have been demonstrated to be effective as biostimulants on plants growth and development and in a wide variety of plants (Harman et al., 2004; Bhardwaj et al., 2014). Some strains/isolates of Trichoderma may have better interaction with certain plant species, which can be called "Trichoderma species/isolate affinity" with some plant species. Trichoderma rhizosphere-competent strains have also been shown beneficial in plant growth and development. Several likely mechanisms have been suggested to explain this phenomenon such as the ability of mineral solubilization and increasing plant nutrient uptake (Altomare et al., 1999). Evidences also suggest that Trichoderma produces plant growth regulatory material and phytohormone such as Indol acetic acid and their analogous (Vinale et al., 2008a; 2012), vitamins, and enzyme leading to stronger root and shoot growth, and organic acids in rhizosphere such as gluconic, citric, and/or fumaric acids that decrease soil $\mathrm{pH}$ (Harman et al., 2004). Therefore, exploration and using plant growth and development promoting Trichoderma species/isolates may be helpful in improving and achieving the sustainable and eco- 
friendly agriculture. Seed germination and seedling vigor mainly depend on seed germination rate, rapidity of root elongation and development during seed germination, and root and shoot fresh and dry weight. There are several mechanisms by which Trichoderma influences the seed germination and seedling vigor (Doni et al., 2014b) by betterment of the parameters which include but are not limited only to secretion of the seed germination stimulating factors and phytohormone (Zheng and Shetty, 2000; Clear and Valic, 2005) as well as enzymes involved in nutrition absorption (Jiang et al., 2011). As questioned Trichoderma species/isolates in improving seed germination, In this study, we observed that $T$. harzianum T969 non-sterilized culture filtrate significantly increased wheat seed germination rate but heat-sterilized culture filtrate did not have any effects. This observation suggests that the influent metabolites are heat-sensitive and become degraded by autoclaving. As demonstrated by the others, the effect of the Trichoderma specie/isolates secreted compounds in seed germination and seedling vigor depends not only on the Trichoderma species/isolate (as what we see in this study) and the type of metabolite(s) but also the plant species responses to the Trichoderma secreted metabolites are important (Gupta and Sharma, 1995; Celar and Valic, 2005; Vinale et al., 2012). Some strains/isolates of Trichoderma may have better interaction with certain plant species, which can be called "Trichoderma species/isolate affinity" with some plant species. In this sense, while culture filtrate of some Trichoderma species/isolates has been reported as stimulant of the seed germination in some plant species (Doni et al., 2014b), some other reports have described seed germination inhibitory effect of other Trichoderma species/isolates (Hajieghrari, 2010). Also, the observed result of Trichoderma cultural filtrate in seed germination and seedling vigor indicative far from to the observed result in introducing the Trichoderma species/ isolate to the spermosphere and rhizosphere. Notably, T. harzianum T969-fortified wheat seeds showed significant increase in germination rate. $T$. harzianum T969 also colonized the emerged rootlet surface, though the colonization was found to be superficially without penetrating in the tissue and injuring seedling rootlet. It seems that Environmental conditions especially in the colonized rhizosphere are the most important factors in what the plant root-Trichoderma interaction will result in. The capability of Trichoderma to colonize the spermosphere and rhizosphere of a plant root especially in root tip region is an important factor in its effectiveness not only in seed germination and promoting seedling growth but also in protection of the plant from soil-borne pathogenic fungi (Howell, 2003). Although we found that other Trichoderma species/isolates also were able to grow and colonize on the entire rootlet surface superficially, some of Trichoderma strains colonized only local sites on the roots. For eliciting increased growth response, Trichoderma must be initially able to establish an interaction with the plant root system. Colonization, surviving and developing of Trichoderma isolates in seed spermosphere and seedling rhizosphere mainly depend on certain compounds in the seed and seedling root exudates such as sugar and other carbohydrates, amino acids and organic acids (Howell, 2003) that lead to root colonization. For example, the highly hydrated polysaccharides of root-secreted mucosal layer and rootderived mono and disaccharides especially root-secreted sucrose are important energy sources that induce Trichoderma growth in the rhizosphere (Hermosa et al., 2012). We observed that T. hamatum T.614 was able to penetrate the rootlet epidermis and outer cortex and develop in the inner tissue leading to some necrotic region in wheat rootlet tissue. This observation did not surprise us since some reports have already highlighted the ability of some Trichoderma isolates to penetrate the root epidermis and colonize mostly through the intercellular spaces with or without causing extensive damage (Yedidia et al., 1999; Hajieghrari, 2010) evolving into a symbiotic rather than a parasitic microorganism. Such symbiotic Trichoderma-plant interaction may lead to direct molecular cross-talk resulting in expression certain genes involved in the promotion of the plant growth and/or in the plant innate defense against plant pathogenic microbes (Vinale et al., 2008). However, in some environmental conditions the symbiotic interaction may lean to pathogenic. The growth and biological activity of Trichoderma in the culture media could alter the chemical content and physical characteristics of the media. $\mathrm{Na}^{+}$and $\mathrm{K}^{+}$ content and $\mathrm{EC}$ and $\mathrm{pH}$ in the culture media were modified. This modification in the growth medium is important since that root colonization and growth on root system as by Trichoderma may result in chemical changes in rhizosphere root system environment. This may result in increment of the insoluble compounds and availability of micronutrients as well as improving in and therefore increased plant nutrient uptake which can help the plant to grow more rapidly and it also enhances plant greenness which results in higher photosynthetic rate. All of these effects lead to will result in increase of the plant photosynthesis resulting in increase of and also carbohydrate metabolism and starch accumulation leading to increased energy availability required for enhancing growth response. The root-Trichoderma interaction establishment and effect of such interaction on plant growth and development as well as its influence on protection of the plant against plant pathogenic fungi in experimental conditions in laboratory are far away from the natural condition in the field (Hajieghrari et al., 2008). It seems that the soil chemical, physical and biological conditions in the field such as type of soil, soil micro flora and soil $\mathrm{pH}$ as well as watering and fertilizer regimes (Kredics et al., 2003) and other soil condition directly affect the receptivity of the plant to the growth-promoting factors as well as and also influences the Trichoderma production of some secondary metabolites and enzymes by Trichoderma having which has the most important role in what consequences will be occurred occur in the rhizosphere environment. These conditions have diverse efficacy on different Trichoderma species/isolates in confronting with a specified plant.

It is well known that biotic and abiotic environment can affect both the plant and Trichoderma in interaction with each other and with other plant pathogens. A better understanding of these interactions and the activity of the Trichoderma isolates/species in promoting plant growth can be achieved in field conditions. As we observed in the field experiments, the growth parameters response to the diverse employed Trichoderma species/isolates was different. $T$. harzianum T.447 had the most significant effect on decreasing stomatal conductivity in the wheat plants compared with other isolates and also the control. It is widely known that stomata are able to sense the changes that occur in the plant surrounding environment and they modify the effect of environmental conditions on plant physiology by controlling the transduction of water and $\mathrm{CO}_{2}$, tuning the metabolism and environment. Lower stomata conductivity leads to lower plant water loss through stomata and on the other hand limited carbon gain and lower photosynthesis. In this case, some Trichoderma species/isolates may cause stress in the plant, leading to changes in plant metabolites 
especially plant hormones which affect the stomata conductivity. Lower stomata conductivity also can affect the plant photosynthesis. However, significant reduction was not observed in the chlorophyll content of the Trichoderma fortified plants. Although Trichoderma isolates did not affect the wheat plants growth parameters, they increased 1000 grain weight in treated plants. G. virens G.525 inoculated plants showed more increase in 1000 grain weight, resulting in better quantitative improvement in the crop productivity and yield.

\section{Materials and Methods}

\section{Seeds source}

Wheat cv. Moghan 3 seeds were used in the experiments. The seeds were obtained from Seed and Plant Certification and Registration Institute, Karaj, Iran. Seeds were disinfected by immersion in $0.5 \%$ hypochlorite sodium $(\mathrm{NaClO})$ for $5 \mathrm{~min}$ before being rinsed and washed thoroughly in sterile distilled water thrice in a laminar air flow cabinet, placed on a sterile blotting paper in sterile dishes for further uses.

\section{Trichoderma isolates}

Four Trichoderma isolates were obtained from the collection of Trichoderma spp. isolates in Iranian Research Institute of Plant Protection (IRIPP), Tehran including T. harzianum T 969, T. harzianum $\mathrm{T} 447, T$. hamatum $\mathrm{T} 614$, and Gliocladium virens G525. An isolate (Trichoderma sp. isolate T) was isolated from a wheat field in Moghan, Iran. The isolates were grown and maintained on Potato Dextrose Agar (PDA) plates and stored at $4{ }^{\circ} \mathrm{C}$.

\section{Preparation of the spore suspension}

Five millimeter diameter mycelia discs were cut from the margin of 7-day old PDA culture of each isolate and from an uncultured PDA plate and were centrally placed on $100 \mathrm{~mL}$ PDA in $250 \mathrm{~mL}$ conical flasks. After incubation at $25^{\circ} \mathrm{C}$ for 14 days, $20 \mathrm{~mL}$ sterile double distilled water was added to each flask and the flasks were shaken at $80 \mathrm{rpm}$ for $30 \mathrm{~min}$. The concentration of the spores in collected water was measured using haemocytometer and it was adjusted to $10^{6}-$ $10^{7}$ spores per milliliter in final spore suspension.

\section{Preparation of the culture filtrate}

Five discs of mycelia agar plugs $(5 \mathrm{~mm}$ diameter) cut from the margin of 7-day old colony of each isolate were inoculated into $100 \mathrm{~mL}$ sterilized Potato Dextrose Broth (PDB) and incubated at $25^{\circ} \mathrm{C}$ for 14 days under constant shaking at $100 \mathrm{rpm}$. For controls, one of the medium flasks was inoculated by sterile distilled water and another one by discs cut from uncultured PDA plate. After centrifugation of the broths, they were filtered through Millipore filter for removing mycelia mats and then passed through $0.2 \mu \mathrm{m}$ membrane filter (FP30/0.2 CA-S, Schleicher and Schuell MicroScience $\mathrm{GmbH}$ ) for removing spores and mycelia mats. One half of the cultural filtrate was autoclaved at $121^{\circ} \mathrm{C}$ for $20 \mathrm{~min}$.

\section{Preparation of the seeds}

The seeds were surface disinfected by immersion in $0.5 \%$ bleach solution for $3 \mathrm{~min}$ then were rinsed and washed in sterile distilled water thrice and air-dried in a laminar air flow cabinet.

\section{Seeds treatment and germination assay}

One hundred seeds were soaked in $10 \mathrm{~mL}$ spore suspension of each isolate and were placed on a sterile blotting paper inside a sterilized Petri dish. One hundred seeds were also placed on a sterile blotting paper in a separate sterile dish and were watered with $10 \mathrm{~mL}$ the autoclaved and non-autoclaved of culture filtrates from each isolates. In each experimental set, two control treatment sets, $10 \mathrm{~mL}$ sterile distilled water and $10 \mathrm{~mL}$ non-inoculated culture filtrate, were conducted. The dishes were incubated at $25^{\circ} \mathrm{C}$. For evaluation of seed germination rate, rapidity of root elongation during seed germination, shoot and rootlet elongation; percentage of seed germination, coleoptile and rootlet weight, and rootlet and coleoptile length of seedling was measured after 48 and 72 hours.

\section{Field experiments and plant growth assay}

The seeds were soaked in spore suspensions and spore-coated seeds were planted in the field. The parameters included the rootlet and shoot length, stem height and weight, root length and weight, total leaf area, head and tiller number, grains number and weight (1000 grain weight). The rootlet and shoot length were measured early tillering stage. Stem length and weight, root length and weight, and head and tiller number were measured at the early ripe stage. The values for total leaf area, head and tiller number, grains number and weight (1000 grain weight) were measured at maturity stages. For root length and weight measurement, the plants were uprooted and the roots were washed under running tap water to remove residual soil. Total chlorophyll content and stomatal conductance of the plants were measured using Chlorophyll Meter SPAD 502 (Konica Minolta Sensing Inc, Japan) and SC-1 Leaf Promoter (Decagon, USA) respectively at the early ripe stage. Also, Total leaf area was measured using LI-3100 Area Meter (Li-COR Biosciences, USA) at grain filling stage. For each measurement, five wheat plants per each row were used and the values are the average of the means of each row in the block.

\section{Experimental design}

In all laboratory experiments including seed germination assay, seedling and rootlet lengths, crown diameter and shoot and rootlet fresh weight study, each treatment was set up in four replications (four Petri dishes) forming a completely randomized design (CRD). In the field part, two experiments were conducted at two different locations simultaneously in the spring of 2014 in Moghan, northwest of Iran. Both field experiments were carried out in four blocks (replications) designed in randomized complete block design (RCBD). Each block contained 15 rows and each row was $5 \mathrm{~m}$ long and received one seed per $5 \mathrm{~cm}$.

\section{Statistical analysis}

The means of the parameters from four replications in all laboratory and field experiments were statistically analyzed by ANOVA followed by Duncan's Multiple Range Test for variable at $1 \%$ and $5 \%$ significant level using SAS software (SAS Institute Inc., Cary, NC, USA) to separate the means. 


\section{Conclusion}

In this study, Trichoderma non-sterilized metabolites had significant effect on wheat (variety Moghan 3) seed germination and seedling vigor, but heat-sterilized metabolites did not have any effects. Significant effects on seed germination and seedling vigor was also observed in the seeds inoculated by Trichoderma spores. In the field, we observed marked effects of the Trichoderma isolates on parameters such as leaves stomata conductivity, 1000 grain weight, ear fresh and dry weights, ear length and stem and root dry weight, but no effect on other evaluated parameters was observed. In overall, some isolates were able to affect growth parameters in aerial organs by colonizing the wheat rhizosphere. Screening of Trichoderma isolates that not only are able to control soil pathogenic fungi but also are able to promote some beneficial growth parameters may help the plant standing in better growth position.

\section{Acknowledgement}

The authors would like to express their special thanks to the Moghan College of Agriculture and Natural Resources, University of Mohaghegh Ardabilli for providing the research field and for all assistance and support during the research.

\section{References}

Altintas S, Bal U (2008) Effects of the commercial product based on Trichoderma harzianum on plant, bulb and yield characteristics of onion. Sci Hort. 116: 219-222.

Altomare C, norvell WA, bjorkman T, harman GE (1999) Solubilization of phosphates and micronutrients by the plant-growth-promoting and biocontrol fungus Trichoderma harzianum rifai 1295-22. Appl Environ Microbiol. 65: 2926-2933.

Anke H, Kinn J, Bergquist KE, Sterner O (1991) Production of siderophores by strains of the genus Trichoderma: isolation and characterization of the new lipophilic coprogen derivative, palmitoylcoprogen. Bio Metals. 4: 176-180.

Badar R Qureshi SA (2012) Use of Trichoderma hamatum alone and in combination with rhizobial isolates as biofertilzer for Improving the growth and strength of sunflower. J Basic Appl Sci Res. 2: 6307-6314.

Bal U, Altintas S (2008) Effects of Trichoderma harizanum on lettuce in protected cultivation. JCEA. 9: 63-70.

Benítez T, Rincón AM, Limónm MC, Codón AC (2004) Biocontrol mechanisms of Trichoderma strains. Int Microbiol. 7: 249-260.

Bhardwaj D, Ansari MW, Sahoo RK, Tuteja N (2014) Biofertilizers function as key player in sustainable agriculture by improving soil fertility, plant tolerance and crop productivity. Microb Cell Fact. 13: 66.

Celar F, Valic N (2005) Effects of Trichoderma spp. and Glicladium roseum culture filtrates on seed germination of vegetables and maize. J Plant Dis Prot. 112: 343-350.

Contreras-Cornejo HA, Macías-Rodríguez L, Cortés-Penagos C, López-Bucio J (2009) Trichoderma virens, a plant beneficial fungus, enhances biomass production and promotes lateral root growth through an auxin-dependent mechanism in Arabidopsis. Plant Physiol. 149: 1579-1592.

De-Santiago A, Quintero JM, Avilés M, Delgado A (2011) Effect of Trichoderma asperellum strain T34 on iron, copper, manganese, and zinc uptake by wheat grown on a calcareous medium. Plant Soil. 342: 97-104.
Doni F, Anizan I, Che Radziah CMZ, Wan Mohtar WY (2014a) Physiological and growth response of rice plants (Oryza sativa L.) to Trichoderma spp. inoculants. AMB Express. 4: 45.

Doni F, Anizan I, Che-Radziah CMZ, Salman AH, Rodzihan MH, Yusoff WMW (2014b) Enhancement of rice seed germination and vigor by Trichoderma spp. ETASR. 7: 4547-4552.

Druzhinina IS, Seidl-Seiboth V, Herrera-Estrella A, Horwitz BA, Kenerley CM, Monte E, Mukherjee PK, Zeilinger S, Grigoriev IV, Kubicek CP (2011) Trichoderma: the genomics of opportunistic success. Nat Rev Microbiol. 9: 749-759.

Entesari M, Sharifzadeh F, Ahmadzadeh M, Farhangfar M (2013) Seed biopriming with Trichoderma species and Pseudomonas fluorescent on growth parameters, enzymes activity and nutritional status of soybean. Intl J Agron Plant Prod. 4: 610-619.

Erper I, Turkkan M, Atanasova L, Druzhinia IS, Karaca, GH, Cebi-Kilicoglu M (2013) Integrated assessment of the mycoparasitic and phytostimulating properties of Trichoderma strains against Rhizoctonia solani. Bulg J Agric Sci. 19: 737-743.

Fuentes-Ramirez L, Caballero-Mellado J (2005) Bacterial biofertilizers In PGPR: biocontrol and biofertilization, ZA Siddiqui (ed) pp. 143-172 Springer, Dordrecht, The Netherlands.

Gentili F, Jumpponen A (2006) Potential and possible uses of bacterial and fungal biofertilizers In Handbook of microbial biofertilizers, ed. MK Rai, pp. 1-28 The Haworth Press NY USA.

Gravel V, Antoun H, Tweddell RJ (2007) Growth stimulation and fruit yield improvement of greenhouse tomato plants by inoculation with Pseudomonas putida or Trichoderma atroviride: Possible role of Indol acetic acid (IAA). Soil Biol Biochem. 39: 1968-1977.

Gupta O, Sharma ND (1995) Effect of fungal metabolites on seed germination and root length of black gram (Phaseolus mango L.). Legume Res. 18: 54-60.

Hajieghrari B (2010) Effects of some Iranian Trichoderma isolates on maize seed germination and seedling vigor. Afr J Biotechnol. 9: 4342-4347.

Hajieghrari B, Torabi-Giglou M, Mohammadi MR, Davari M (2008) Biological potential of some Iranian Trichoderma isolates in the control of soilborne plant pathogenic fungi. Afr J Biotechnol. 7: 967-972.

Harman GE (2006) Overview of mechanisms and uses of Trichoderma spp. Phytopathol. 96: 190-194.

Harman GE, Howell CR, Viterbo A, Chet I, Lorito M (2004) Trichoderma species - opportunistic, avirulent plant symbiont. Nat Rev Microbiol. 2: 43-56.

Hermosa R, Viterbo A, Chet I, Monte E (2012) Plantbeneficial effects of Trichoderma and of its genes. Microbiol. 158: 17-25.

Hicks E, Bienkowski D, Braithwaite M, McLean K, Fallon R, Stewarti A (2014) Trichoderma strains suppress Rhizoctonia diseases and promote growth of potato. Phytopathol Mediterr. 53: 502-514.

Howell CR (2003) Mechanisms employed by Trichoderma species in the biological control of plant diseases: the history and evolution of current concepts. Plant Dis. 87: 410.

Hoyos-Carvajal L, Orduz S, Bissett J (2009) Growth stimulation in bean (Phaseolus vulgaris L) by Trichoderma. Biol Control. 51: 409-416. 
Jiang X, Geng A, He N, Li Q (2011) New isolates Trichoderma viride strain for enhanced cellulolytic enzyme complex production. J Biosci Bioeng. 111: 121-127.

John RP, Tyagi RD, Prévost D, Brar SK, Pouleur S, Surampalli RY (2010) Mycoparasitic Trichoderma viride as a biocontrol agent against Fusarium oxysporum fsp. adzuki and Pythium arrhenomanes and as a growth promoter of soybean. Crop Prot. 29: 1452-1459.

László Kredics L, Antal Z, Manczinger L, Szekeres A, Kevei F, Nagy E (2003) Influence of environmental parameters on Trichoderma strains with biocontrol potential. Food Technol Biotechnol. 41: 37-42.

Li RX, Cai F, Pang G, Shen QR, Li R, Chen,W (2015) Solubilization of phosphate and micronutrients by Trichoderma harzianum and its relationship with the promotion of tomato plant growth. PLoS ONE. 10: $\mathrm{e} 0130081$

Lu X, Tombolini R, Woo S, Zeilinger S, Lorito M, Jansson JK (2004) In vivo study of Trichoderma-pathogen-plant interactions, using constitutive and inducible green fluorescent protein reporter systems. Appl Environ Microbiol. 70: 3073-3081

Maag D, Kandula DRW Müller C, Mendoza-Mendoza A, Wratten SD, Stewart A Rostás M (2014) Trichoderma atroviride LU132 promotes plant growth but not induced systemic resistance to Plutella xylostella in oilseed rape. Bio Control. 59: 241-252.

Martínez-Medina A, Del Mar Alguacil M, Pascual JA, Van Wees SCM (2014) Phytohormone profiles induced by Trichoderma isolates correspond with their biocontrol and plant growth-promoting activity on melon plants. J Chem Ecol. 40: 804-815.

Mazahebi M, Nemati H, Rouhani H, Tehranifar A, Moghadam EM, Kaveh H (2011) How may Trichoderma application affect vegetative and qualitative traits in tulip "darwin hybride" cultivar. J Biol Environ Sci. 5: 177-182.

Mihov M, Tringovska I (2010) Energy efficiency improvement of greenhouse tomato production by applying new biofertilizers. Bulg J Agric Sci. 16: 454-458.

Morsy EM, Abdel-Kawi KA, Khalil MNA (2009) Efficiency of Trichoderma viride and Bacillus subtilis as biocontrol agents gainst Fusarium solani on tomato plants. Egypt J Phytopathol. 37: 47-57.

Nagananda GS, Das A, Bhattacharya S, Kalpana T (2010) In vitro studies on the effects of biofertilzers (azotobacter and rhizobium) on seed germination and development of Trigonella foenum-graecum $\mathrm{L}$ using a novel glass marble containing liquid medium. Intl J Botany. 6: 394-403.

Porras M, Barrau C, Romero F (2007). Effects of soil solarization and Trichoderma on strawberry production. Crop Prot. 26: 782-787.

Raats PAC (2012) Effect of Trichoderma species on damping off diseases incidence, some plant enzymes activity and nutritional status of bean plants. Int J Agr Env. 2: 13-25.

Raman J (2012) Response of Azotobacter, Pseudomonas and Trichoderma on growth of apple seedling international conference on biological and life sciences IPCBEE, IACSIT Press, Singapore.
Saravanakumar K, Shanmuga Arasu V, Kathiresan K (2013) Effect of Trichoderma on soil phosphate solubilization and growth improvement of Avicennia marina. Aquat Bot. 104: 101-105.

Shanmugaiah V, Balasubramanian N, Gomathinayagam S, Monoharan PT, Rajendran A (2009) Effect of single application of Trichoderma viride and Pseudomonas fluorences on growth promotion in cotton plants. Afr J Agric Res. 4: 1220-1225.

Sharma P, Patel AN, Saini MK, Deep S (2012) Field demonstration of Trichoderma harzianum as a plant growth promoter in wheat (Triticum aestivum L). J Agr Sci. 4: 6573.

Topolovec-Pintarić S, Žutiće I, Đermiće E (2013) Enhanced growth of cabbage and red beet by Trichoderma viride. Acta Agric Slov. 101: 87-92.

Vinale F, Sivasithamparamb K, Ghisalberti EL, Marra R, Barbetti MJ, Li H, Woo SL, Lorito M (2008a) A novel role for Trichoderma secondary metabolites in the interactions with plants. Physiol Mol Plant Path. 72: 80-86.

Vinale F, Sivasithamparam K, Ghisalberti EL, Ruocco M, Wood S, Lorito M (2012) Trichoderma secondary metabolites that affect plant metabolism. Nat Prod Commun. 7: 1545-1550.

Vinale F, Sivasithamparam K, Ghisalberti EL, Marra R, Woo SL, Lorito M (2008b) Trichoderma-plant-pathogen interactions. Soil Biol Biochem. 40: 1-10.

Vinale F, Manganiello G, Nigro M, Mazzei P, Piccolo A, Pascale A, Ruocco M, Marra R, Lombardi N, Lanzuise S, Varlese R, Cavallo P, Lorito M, Woo SL (2014) A novel fungal metabolite with beneficial properties for agricultural applications. Molecules. 19: 9760-9772.

Windham MT, Elad Y, Baker R (1986) A mechanism for increased plant-growth induced by Trichoderma spp. Phytopathol. 76: 518-521.

Yadav J, Verma JP, Tiwari KN (2011) Plant growth promoting activities of fungi and their effect on chickpea plant growth. AJBS. 4: 291-299.

Yedidia I, Benhamou N, Chet I (1999) Induction of defense responses in cucumber (Cucumis sativus L.) by the biocontrol agent Trichoderma harzianum. Appl Environ Microbiol. 65: 1061-1070.

Zheng Z, Shetty K (2000) Enhancement of pea (Pisum sativm) seedling vigor and associated phenolic content by extraction of apple pomace fermented with Trichoderma spp. Proc Bioch. 36: 79-84. 